\title{
A Study on the Durability of Dispersive Soils Improved by Alum in Western Jilin Province of China
}

\author{
Xiaoqing Yuan $\left(\mathbb{D}\right.$, Xi Wang $\mathbb{D}$, Hui'e Chen $\mathbb{D}^{D}$, Zhiyong Shi $\mathbb{D}$, Bin Shi $\mathbb{D}^{\circ}$, and Cencen Niu \\ College of Construction Engineering, Jilin University, Changchun 130026, China \\ Correspondence should be addressed to Hui'e Chen; chenhe@jlu.edu.cn
}

Received 30 June 2021; Accepted 18 August 2021; Published 31 August 2021

Academic Editor: Tianshou Ma

Copyright (c) 2021 Xiaoqing Yuan et al. This is an open access article distributed under the Creative Commons Attribution License, which permits unrestricted use, distribution, and reproduction in any medium, provided the original work is properly cited.

\begin{abstract}
Dispersive soil, which has the characteristics of low erosion resistance and high dispersibility in water, is the main reason for the channel slope failure that happened in the planning area of the Western Alkaline Treatment project in Jilin Province. Therefore, the study focused on the improvement of dispersive soil. In this research, pinhole test and crumb test were conducted on the soil under varying percentages of alum $(1 \%, 1.5 \%, 2 \%, 2.5 \%$, and $3 \%)$. Results indicated that alum can reduce the dispersivity of soil distinctly, and the optimal content of alum was $2.5 \%$. This research also investigated the durability of 2.5\%-alum-improved dispersive soil for dispersibility under the condition of freeze-thaw cycle. The soil samples with $2.5 \%$ alum content were subjected to pinhole test, crumb test, double hydrometer test, and percentage of exchangeable sodium ion test under the different number of freeze-thaw cycles. The results showed that the $2.5 \%$-alumimproved soil was unaffected by the number of freeze-thaw cycles, which illustrated that alum can be used to improve soil dispersivity in engineering practice.
\end{abstract}

\section{Introduction}

Dispersive soil is a kind of cohesive soil prone to loss, in which soil particles will disperse under a very low hydraulic gradient when the repulsion force between soil particles exceeds the attraction force in low salinity or pure water [1]. Dispersive soil is extremely vulnerable to water erosion and dispersion loss, so it is likely to cause piping on structures such as drains and embankments [2], seriously endangering engineering safety. Obvious erosion phenomena can be seen in Qian'an area of Jilin Province. The water in the puddle on the roadside was turbid for a long time, and cracks occurred after it dried up (see Figure 1). Tests have proved that the soil samples have dispersive characteristics, which are related to the destruction of the channel slope and adversely affect the durability of the soil in this area.

To enhance the safety of projects while reducing engineering loss, the most direct and effective method is to improve the dispersive soil. Dispersibility is mainly influenced by the chemical properties and mineral species of the pore water [3]; the content of $\mathrm{Na}^{+}$and the $\mathrm{pH}$ of the soil have especially the greatest influence. Therefore, modifiers are usually used to replace sodium ions on the surface of soil particles to reduce dispersivity. Gao et al. [4], Gidday and Mittal [5], and Consoli et al. [6] used lime; Mohanty et al. [7], Sihag et al. [8], and Yang [9] used cement; and Savaş et al. [10], Premkumar et al. [11], and Yan et al. [12] used fly ash to improve dispersive soils, which all yielded good improvement results. Studies commonly use the above materials to improve dispersive soils, but alum-soil interactions are less studied. Alum has a higher solubility in water than lime and is environmentally friendly and has a better improvement in dispersivity. Ouhadi and Goodarzi [13] improved dispersive soils with alum, which resulted in a significant reduction in dispersivity and increased the plasticity index and compressibility of the soil. Although these solutions reduce the dispersivity of the soil, there are few applications of improved soil in engineering effects. The soil samples were part of seasonal frozen soil which has undergone freeze-thaw cycles repeatedly in Qian'an. However, it is not clear whether the dispersibility will be affected by the freeze-thaw cycle. Consequently, it is necessary to investigate 


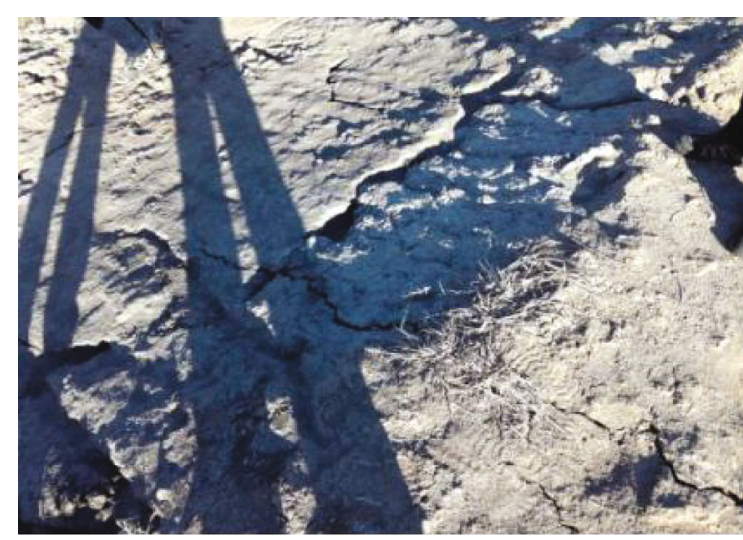

(a)

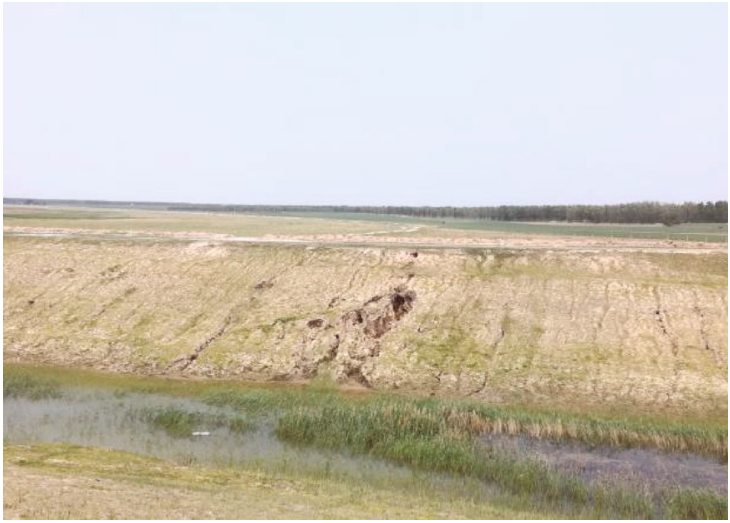

(c)

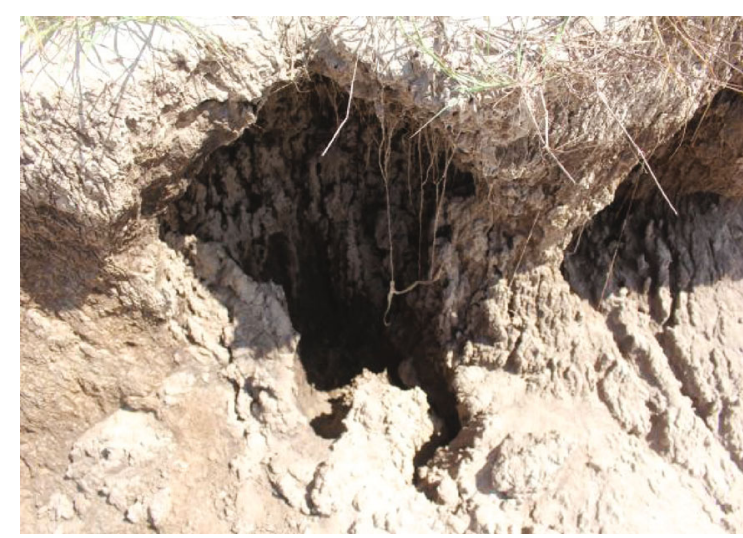

(b)

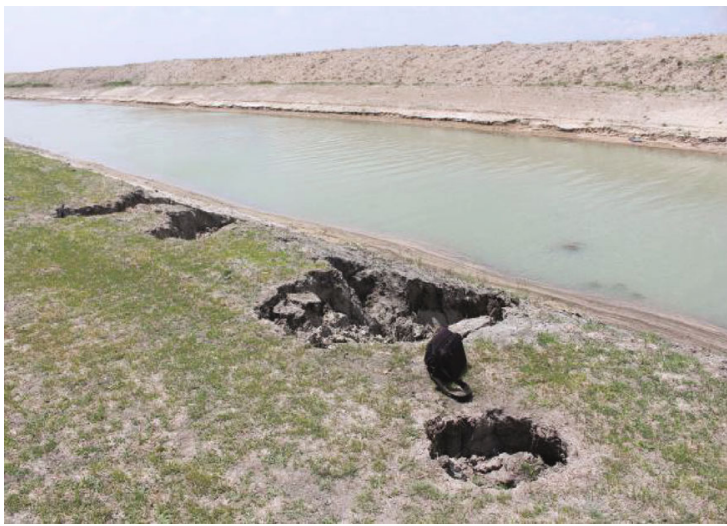

(d)

FIGURE 1: Erosion on the surface of the soil layer: (a) soil crack and (b-d) slope destruction.

TABLE 1: Basic properties of soil samples.

\begin{tabular}{|c|c|c|c|c|c|c|c|c|c|c|c|}
\hline \multicolumn{3}{|c|}{ Particle composition (\%) } & \multirow[b]{2}{*}{$\begin{array}{l}\text { Liquid } \\
\text { limit } \\
W_{\mathrm{L}}(\%)\end{array}$} & \multirow[b]{2}{*}{$\begin{array}{c}\text { Plastic } \\
\text { limit } \\
W_{\mathrm{P}}(\%)\end{array}$} & \multirow[b]{2}{*}{$\begin{array}{l}\text { Plasticity } \\
\text { index } I_{\mathrm{P}}\end{array}$} & \multicolumn{2}{|c|}{ Percussive parameters } & \multirow[b]{2}{*}{$\mathrm{pH}$} & \multicolumn{3}{|c|}{ Soluble salt content (\%) } \\
\hline$>0.075 \mathrm{~mm}$ & $0.005 \sim 0.075 \mathrm{~mm}$ & $<0.005 \mathrm{~mm}$ & & & & $\begin{array}{l}\text { Maximum } \\
\text { dry density } \\
\left(\mathrm{g} / \mathrm{cm}^{3}\right)\end{array}$ & $\begin{array}{l}\text { Optimum } \\
\text { moisture } \\
\text { content }(\%)\end{array}$ & & $\mathrm{Na}^{+}$ & $\begin{array}{c}\mathrm{Ca}^{2+}, \\
\mathrm{Mg}^{2+}, \mathrm{K}^{+}\end{array}$ & $\begin{array}{l}\mathrm{SO}_{4}{ }^{2-} \\
\mathrm{CO}_{3}{ }^{2-}\end{array}$ \\
\hline 5.3 & 44.77 & 49.92 & 19.64 & 11.52 & 8.12 & 1.69 & 17.2 & 7.58 & 0.0116 & 0.0101 & 0.0449 \\
\hline
\end{tabular}

the durability of the soil under freeze-thaw cycles, which has guiding significance for engineering practice.

Based on these, the soil samples were taken from Qian'an, the seasonal frozen area of Jilin Province. The study explored the optimal amount of alum by setting different blending amounts, respectively, and analyzed the relationship between durability and the number of freeze-thaw cycles.

\section{Test Materials}

2.1. Engineering Properties of Soil Samples. The soil samples were taken from Qian'an area, Songyuan, northwestern Jilin Province, which is the planning area of the Western Alkaline Treatment project and has a high degree of soil salinization. The basic properties of the soil samples are shown in Table 1. The mineral composition of the soil samples is mainly primary minerals, with the highest content of quartz, followed by sodium feldspar, and the clay minerals are mainly kaolinite and montmorillonite. The relative mineral contents are shown in Table 2 . The results of the soluble salt content and mineral analysis suggest that the soil samples have intrinsic factors to disperse.

2.2. Dispersibility Identification of Soil Samples. The dispersibility of the soil samples was identified by double hydrometer test [14], pinhole test [15], crumb test [16], and percentage of exchangeable sodium ion test [17]. The soil was dispersive soil, and the results are shown in Table 3.

In the pinhole test, the soil sample was made into $\varphi 37$ $\mathrm{mm} \times 38.1 \mathrm{~mm}$ through hydrostatic method and pierced with a $1 \mathrm{~mm}$ diameter pinhole. The $50 \mathrm{~mm}$ water head was adopted, and water flowed through the small hole for 5 min. Finally, the erosion of a small hole by the water flow was observed, so was the water flow and turbidity. The results (see Figure 2) showed that the soil was dispersive soil.

In the crumb test, the $1 \mathrm{~cm}^{3}$ cubic in situ soil sample was taken and submerged in a beaker with $200 \mathrm{ml}$ distilled water for 5-10 min. Then, the disintegration of the soil sample was 
TABLE 2: Relative mineral content.

\begin{tabular}{lcccccccc}
\hline & & \multicolumn{3}{c}{ Content of various minerals in whole soil (\%) } & \multicolumn{2}{c}{$\begin{array}{c}\text { Relative content of clay } \\
\text { minerals (\%) }\end{array}$} \\
\hline Kaolinite & Montmorillonite & Quartz & Calcite & Sodium feldspar & Hematite & Calcium sulfate & Kaolinite & Montmorillonite \\
7 & 6 & 43 & 9 & 25 & 7 & 3 & 53.85 & 46.15 \\
\hline
\end{tabular}

TABLE 3: The results of soil sample dispersibility determination.

\begin{tabular}{lccccc}
\hline $\begin{array}{l}\text { Double hydrometer } \\
\text { test } \\
\text { Dispersion (\%) }\end{array}$ & $\begin{array}{c}\text { Water head } \\
(\mathrm{mm})\end{array}$ & $\begin{array}{c}\text { Pinhole test } \\
(\mathrm{min})\end{array}$ & $\begin{array}{c}\text { End pinhole } \\
(\mathrm{mm})\end{array}$ & Crumb test & \multicolumn{2}{c}{$\begin{array}{c}\text { Percentage of exchangeable } \\
\text { sodium ion test }\end{array}$} & ESP (\%) \\
\hline 77.52 & 50 & 5 & 1.9 & $\begin{array}{c}\text { Disintegrated in 2 min; an easily } \\
\text { visible cloud of suspended colloids }\end{array}$ & 29.8 \\
\hline
\end{tabular}

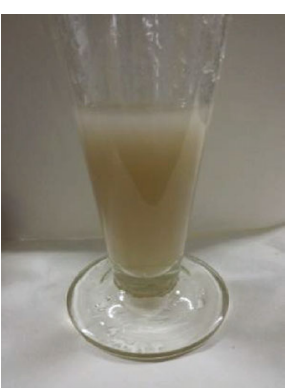

(a)

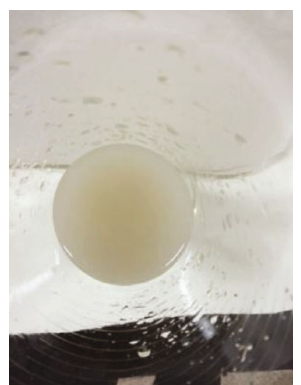

(b)

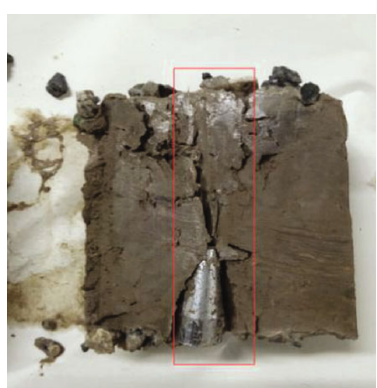

(c)

FIgURe 2: Results of pinhole test: $(a, b)$ water turbidity situation and (c) end pinhole.

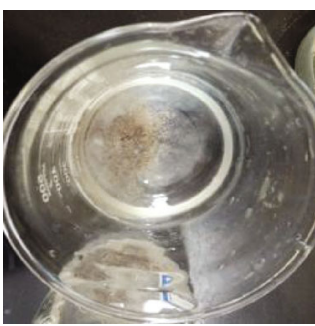

(a)

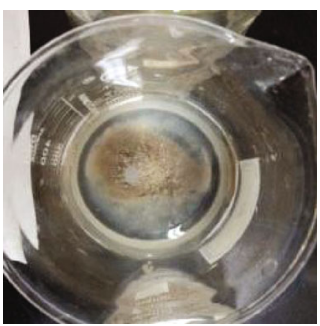

(b)

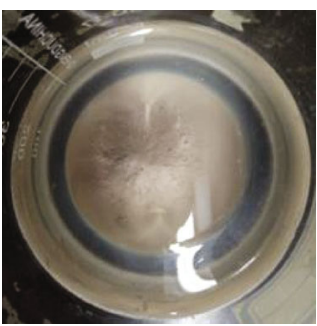

(c)

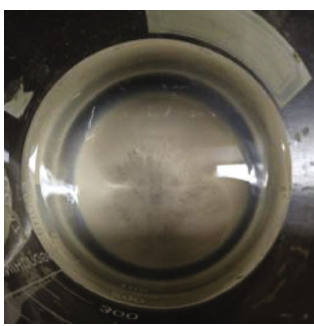

(d)

Figure 3: Disintegration of soil samples in crumb test: (a) $0 \mathrm{~min}$, (b) $2 \mathrm{~min}$, (c) $1 \mathrm{~h}$, and (d) $6 \mathrm{~h}$.

TABLE 4: Results of the double hydrometer test.

Percent finer $(0.005 \mathrm{~mm})$ aperture size dispersing agent

\begin{tabular}{|c|c|c|}
\hline 52.407 & 67.605 & 77.52 \\
\hline
\end{tabular}

TABLE 5: Results of the percentage of exchangeable sodium ion test.

\begin{tabular}{lcc}
\hline $\begin{array}{l}\text { Exchangeable sodium ion } \\
\text { content }\end{array}$ & $\begin{array}{c}\text { Total cation } \\
\text { exchange }\end{array}$ & $\begin{array}{c}\text { ESP } \\
(\%)\end{array}$ \\
\hline 0.525 & 1.756 & 29.8 \\
\hline
\end{tabular}

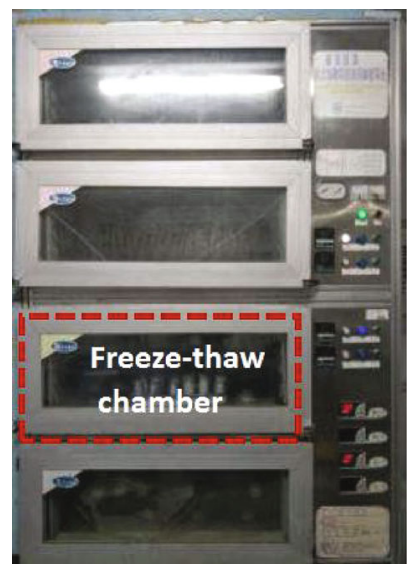

FIgURE 4: Freeze-thaw cycle test apparatus. 


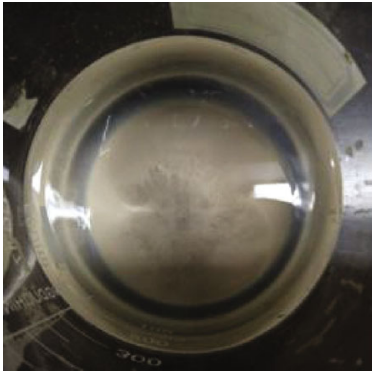

(a)

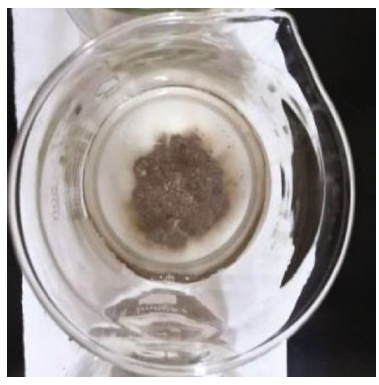

(d)

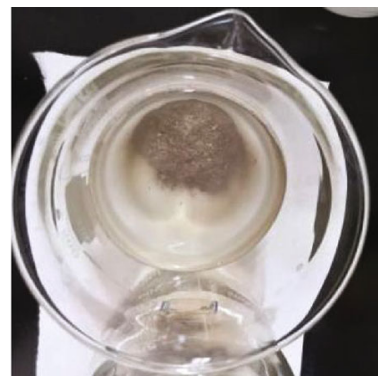

(b)

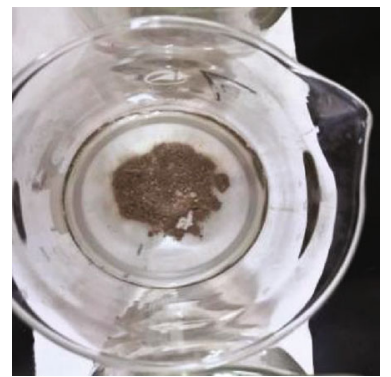

(e)

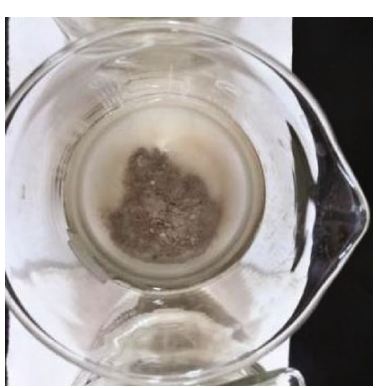

(c)

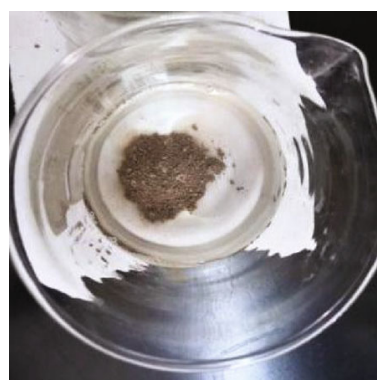

(f)

Figure 5: Observation of the crumb test: (a) $0 \%$ alum, (b) $1 \%$ alum, (c) $1.5 \%$ alum, (d) $2 \%$ alum, (e) $2.5 \%$ alum, and (f) $3 \%$ alum.

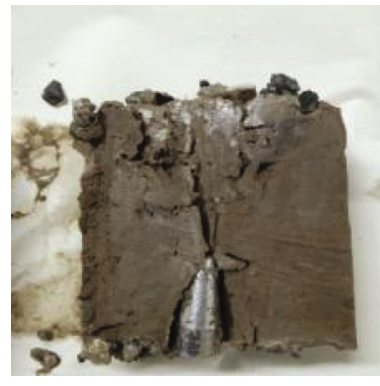

(a)

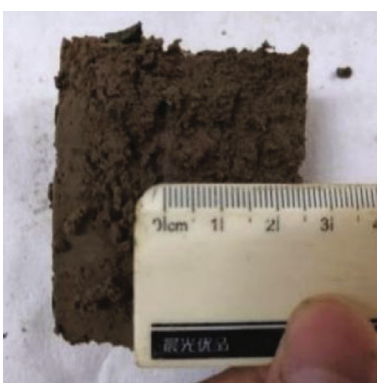

(e)

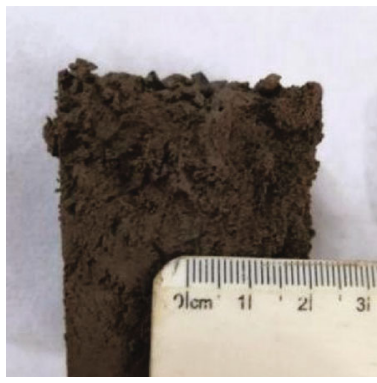

(b)

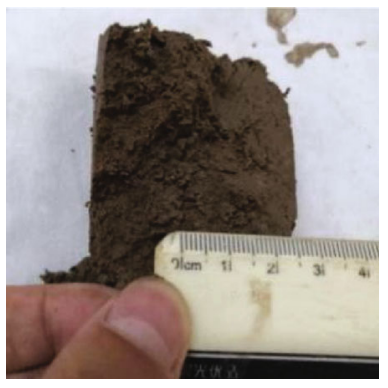

(f)

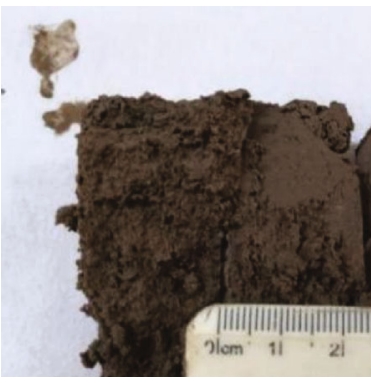

(c)

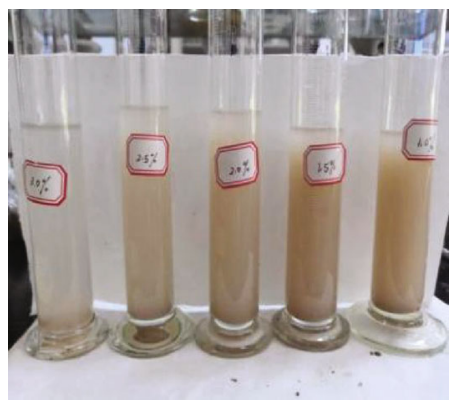

(g)

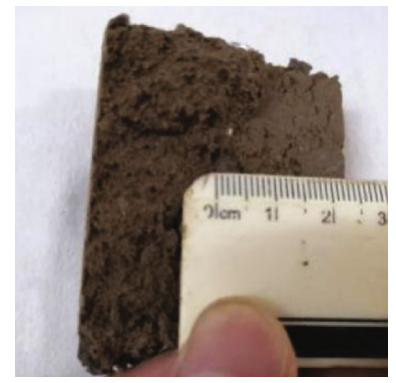

(d)

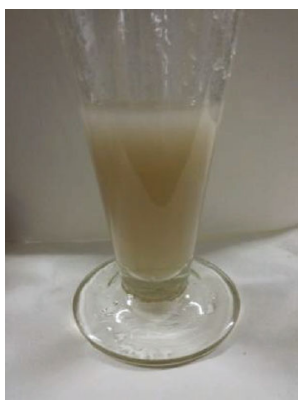

(h)

Figure 6: Observation of the pinhole test: (a) $0 \%$ alum, (b) $1 \%$ alum, (c) $1.5 \%$ alum, (d) $2 \%$ alum, (e) $2.5 \%$ alum, (f) $3 \%$ alum, and (g, h) turbidity of water flow (from left to right are mixed with $3 \%, 2.5 \%, 2 \%, 1.5 \%, 1 \%$ alum, and 0 alum).

TABLE 6: Results of the double hydrometer test and the percentage of exchangeable sodium ion test for the soil samples treated with $2.5 \%$ alum.

\begin{tabular}{|c|c|c|c|c|c|c|}
\hline \multirow[b]{2}{*}{$\begin{array}{l}\text { Mixture } \\
\text { amount (\%) }\end{array}$} & \multicolumn{3}{|c|}{ Double hydrometer test } & \multicolumn{3}{|c|}{ Percentage of exchangeable sodium ion test } \\
\hline & $\begin{array}{l}\text { Percent finer }(0.005 \\
\text { Without a dispersing } \\
\text { agent }\end{array}$ & $\begin{array}{l}\text { m) aperture size } \\
\text { With a dispersing } \\
\text { agent }\end{array}$ & $\begin{array}{l}\text { Dispersion } \\
\quad(\%)\end{array}$ & $\begin{array}{l}\text { Exchangeable sodium } \\
\text { ion content }\end{array}$ & $\begin{array}{c}\text { Total cation } \\
\text { exchange }\end{array}$ & $\operatorname{ESP}(\%)$ \\
\hline 2.5 & 3.35 & 18.24 & 18.37 & 0.29 & 15.6 & 1.86 \\
\hline
\end{tabular}




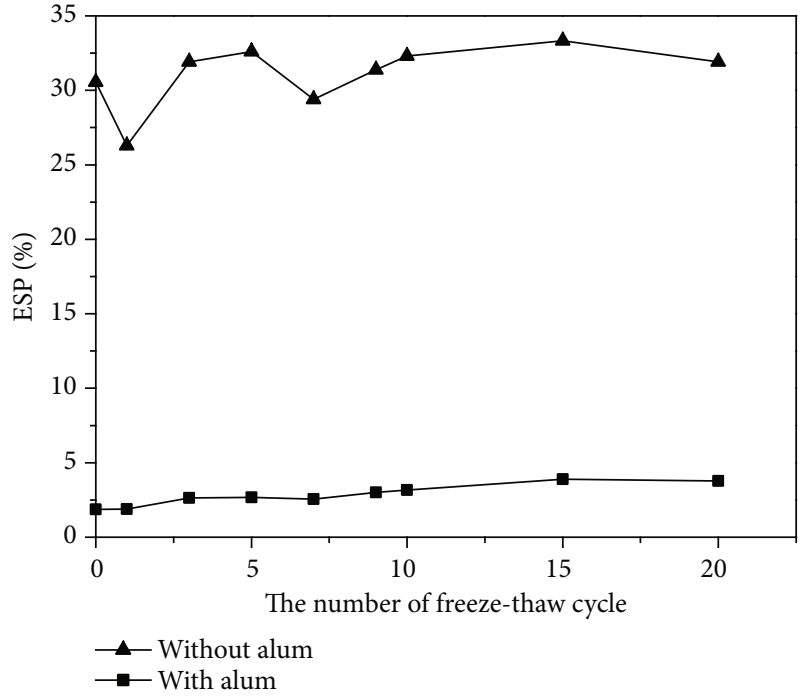

FIGURE 7: Variation of ESP with the number of freeze-thaw cycles under soil treated with $2.5 \%$ alum.

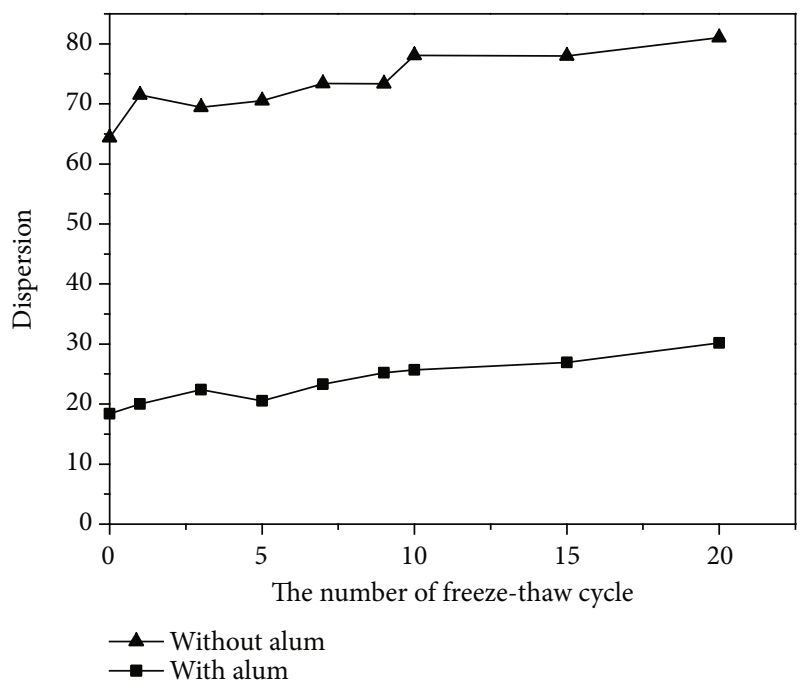

FIGURE 8: Variation of dispersion with the number of freeze-thaw cycles under soil treated with $2.5 \%$ alum.

observed. The soil disintegrated quickly in $2 \mathrm{~min}$, and turbidity could be seen near the soil (see Figure 3 ). The test proved that the soil was dispersive soil.

In the double hydrometer test, the soil sample was carried out twice to measure the percent finer $(0.005 \mathrm{~mm})$ aperture size. The first time the soil sample was boiled with a dispersing agent added; the second time, the soil sample was neither boiled nor dispersing agent added. The dispersion of the soil sample was calculated according to

Dispersion $=\frac{\text { passing } 5 \mu \mathrm{m} \text { under vacuum condition }}{\text { passing } 5 \mu \mathrm{m} \text { under normal condition }} \times 100 \%$.
Previous studies on dispersion discrimination standards are as follows: for nondispersive soil, the dispersion was < $30 \%$; for transitional soil, the dispersion reached $30-50 \%$; and for dispersive soil, the dispersion was $>50 \%$. The dispersion in the soil sample (see Table 4) was $77.52 \%,>50 \%$, which proved that the soil was classified as dispersive soil.

The percentage of exchangeable sodium ion test is a measure of the ratio of the exchangeable $\mathrm{Na}^{+}$content to the total exchangeable cations (CEC) ESP, as shown in

$$
\mathrm{ESP}=\frac{\mathrm{C}_{\mathrm{Na}^{+}}}{\mathrm{CEC}} \times 100 \% .
$$

For nondispersive soil, ESP $<7$; for transitional soil, ESP reached 7-10; and for dispersive soil, ESP $>10$. ESP in the soil sample (see Table 5) was $29.8 \%,>10 \%$, so the soil was classified as dispersive soil.

Based on the results of the above four tests, they all proved that the soil samples had dispersive characteristics.

\section{Test Methods}

3.1. Specimen Preparation. The soil samples were obtained from Qian'an area through a series of disposal processes, dried, crushed, and then sieved through a $2 \mathrm{~mm}$ sieve. To investigate the effect of alum on the durability of the soil samples, variations in the dispersibility of the laboratory soil samples due to the addition of alum were examined. Tests were done for percentages of alum mixed with soil. The soil samples were divided into two groups; one was mixed with $1 \%, 1.5 \%, 2 \%, 2.5 \%$, and $3 \%$ alum by mass fraction, respectively, while the other was mixed with the same mass of untreated soil samples. The step to treat the samples was to identify different influences through the same supplement and to eliminate the effects of differences in mass. Afterwards, the soil samples were mixed with distilled water in a spray bottle to the optimum moisture content of $17.2 \%$ and then sealed in a cling film and left for $24 \mathrm{~h}$ to ensure adequate moisture redistribution. Then, the soil samples were made into $\varphi 39.1 \times 80 \mathrm{~mm}$ size with $95 \%$ compaction to make them reach the maximum dry density, and the specimens were sealed and wrapped with cling film after preparation to prevent water evaporation.

3.2. Durability Test. To simulate the freeze-thaw condition of soil under natural conditions, freeze-thaw cycle test was conducted in the "comprehensive simulation platform for freeze-thaw test of soil in super cold environment" made by Jilin University (see Figure 4). The temperature was monitored by temperature sensors in the upper and lower temperature control chambers to adjust the temperature inside the chamber so that the temperature inside the chamber was continuously maintained at the set temperature. The sealed soil samples were placed in the apparatus. The freezing temperature was set at $-20^{\circ} \mathrm{C}$ and the thawing temperature was $25^{\circ} \mathrm{C}$, and the number of freeze-thaw cycles was set at $1,3,5,7,9,10,15$, and 20 times, respectively.

3.3. Dispersibility Test. Pinhole test [15] simulates water flow through soil cracks, in which process is intuitive, and its 


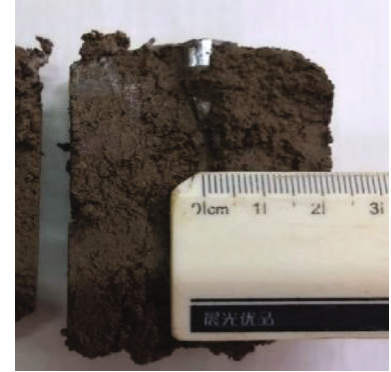

(a)

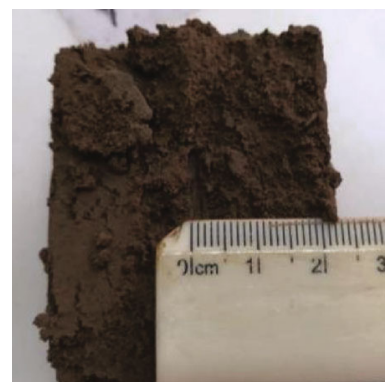

(b)

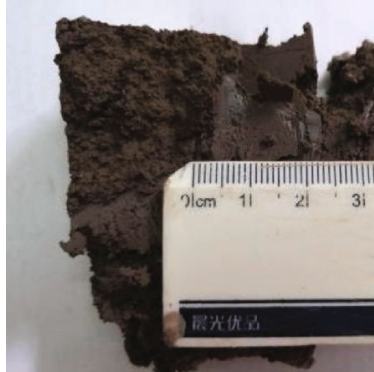

(c)

FIGURE 9: Results of the pinhole test with different freeze-thaw cycles: (a) untreated 0 times, (b) untreated 20 times, and (c) alum-treated 20 times.

TABle 7: Pinhole test results.

\begin{tabular}{|c|c|c|c|c|c|c|}
\hline \multirow{2}{*}{$\begin{array}{l}\text { The number of } \\
\text { freeze-thaw cycles }\end{array}$} & \multicolumn{2}{|c|}{ Without alum } & \multirow[b]{2}{*}{$\begin{array}{c}\text { Dispersion } \\
\text { identification }\end{array}$} & \multicolumn{2}{|c|}{ With alum } & \multirow[b]{2}{*}{$\begin{array}{c}\text { Dispersion } \\
\text { identification }\end{array}$} \\
\hline & Water turbidity & $\begin{array}{c}\text { End pinhole } \\
\text { diameter }(\mathrm{mm})\end{array}$ & & Water turbidity & $\begin{array}{c}\text { End pinhole } \\
\text { diameter }(\mathrm{mm})\end{array}$ & \\
\hline 0 & Turbid & 1.8 & Dispersive & Clear & 1.0 & Nondispersive \\
\hline 1 & Turbid & 1.6 & Dispersive & Clear & 1.0 & Nondispersive \\
\hline 3 & Very cloudy & 2.0 & Highly dispersive & Clear & 1.0 & Nondispersive \\
\hline 5 & Turbid & 1.7 & Dispersive & Clear & 1.0 & Nondispersive \\
\hline 7 & Very cloudy & 2.0 & Highly dispersive & Clear & 1.0 & Nondispersive \\
\hline 9 & Very cloudy & 2.0 & Highly dispersive & Clear & 1.0 & Nondispersive \\
\hline 10 & Very cloudy & 2.0 & Highly dispersive & Clear & 1.0 & Nondispersive \\
\hline 15 & Very cloudy & 2.0 & Highly dispersive & Clear & 1.0 & Nondispersive \\
\hline 20 & Very cloudy & 2.0 & Highly dispersive & Clear & 1.0 & Nondispersive \\
\hline
\end{tabular}

results are generally considered highly reliable [1]. Crumb test [16] is based on the colloidal chemistry point of view [18], which is second in credibility to the pinhole test [19]. Therefore, these two tests were chosen to identify the dispersibility of the improved soil sample and explore the optimal alum mixture quantity. Double hydrometer test [14] and percentage of exchangeable sodium ion test [17] were chosen to verify the optimal mixture quantity. Finally, the four tests were to determine the dispersibility of the soil improved by the optimal alum content under the condition of freeze-thaw cycle.

\section{Results and Discussion}

4.1. Variation of Soil Dispersibility with the Amount of Alum Admixture. The incorporation of alum has an obvious effect on the improvement of dispersive soil. The results of the crumb test are shown in Figure 5. It can be seen that the colloidal clouding decreases with the increase of alum admixture. Without alum addition, the reaction is severe, and a cloud of suspended colloids can be seen easily. At $1 \%, 1.5 \%$, and $2 \%$ addition, the disintegration is not obvious, and the water is slightly cloudy, which shows the soil is classified as transitional soil. At $2.5 \%$ and $3 \%$ addition, there is no reaction in water, so it can be proved as nondispersive soil.

Figure 6 shows the results of the pinhole test. When no alum is added, the hole size after the test is $2(\mathrm{~mm})$, and the water collected is pretty invisible. When the soil is mixed with alum, the pinholes are not eroded, and none of the pinholes' diameters have changed, all being $1 \mathrm{~mm}$. By observing the turbidity of water flow, it is found that the more alum doping, the clearer the water is. When the admixture amount is $1 \%, 1.5 \%$, and $2 \%$, the water collected is turbid, so the soil is identified as transitional soil; when the admixture amount reaches $2.5 \%$ and $3 \%$, the water is clear, identified as nondispersive soil.

No matter for pinhole test or crumb test, the incorporation of alum can improve the soil sample into transitional soil or nondispersive soil, and the improvement effect is more obvious with the increase of the incorporation of alum. It can be improved in nondispersive soil when the incorporation amount reaches $2.5 \%$ and $3 \%$. Therefore, the optimal mixture amount is at least $2.5 \%$. Therefore, the double hydrometer test and the percentage of exchangeable sodium ion test (see Table 6) are used to confirm the optimal quantity. Both of them show that $2.5 \%$ alum mixture can turn dispersive soil to nondispersive soil. Hassanlourad et al. [20] proved that the addition of alum resulted in an increase in shear strength up to $50 \%$ and that further increase in alum content led to a reduction in strength and brittleness. Furthermore, considering the cost issue, $2.5 \%$ is identified as the optimal mixture quantity.

The dispersion mechanism of dispersive soil is mainly influenced by the sodium ions and acidity on the surface of the soil. Sodium ions, as cations, have a small number of 


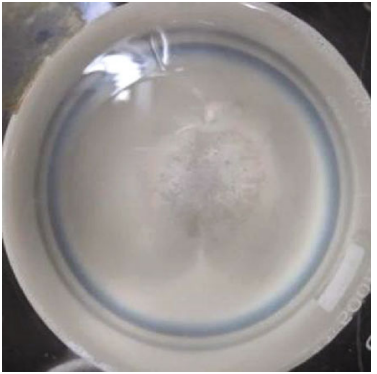

(a)

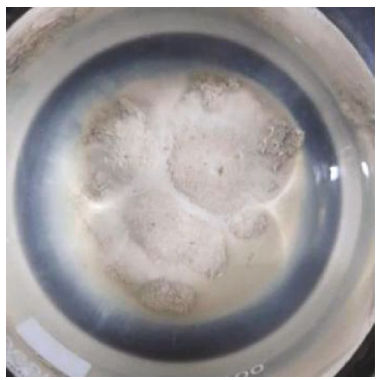

(d)

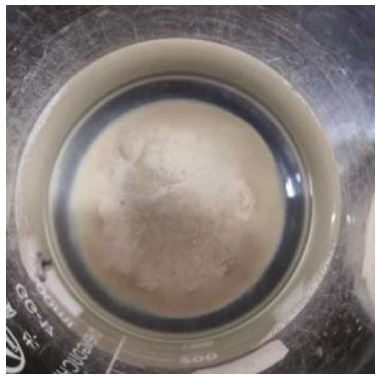

(g)

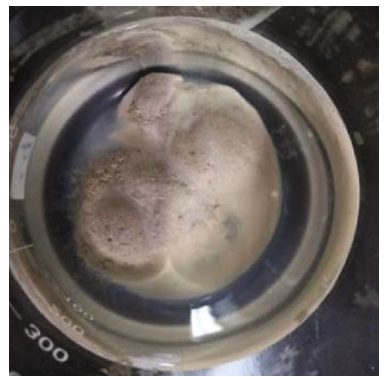

(b)

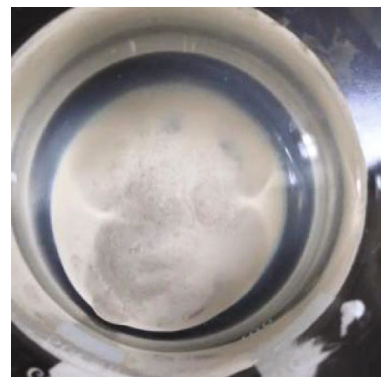

(e)

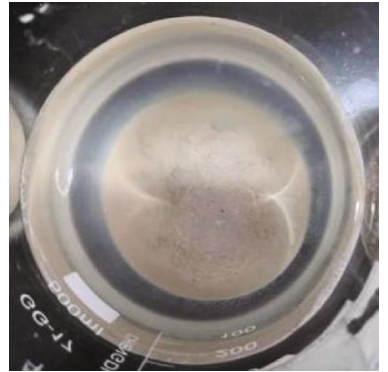

(h)

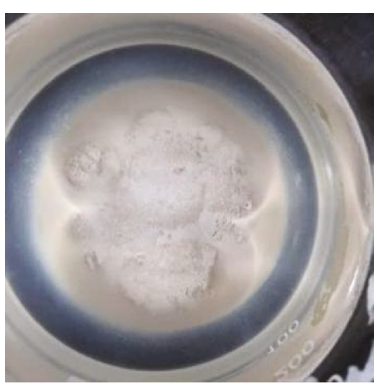

(c)

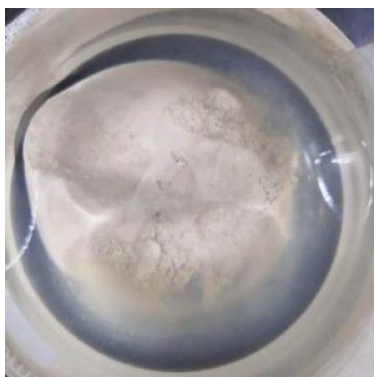

(f)

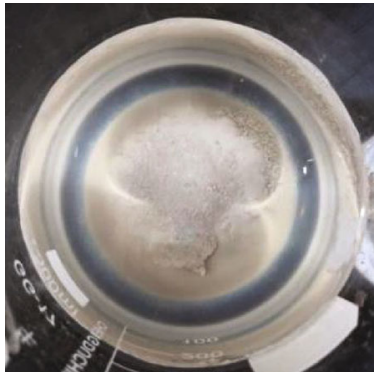

(i)

Figure 10: Results of the crumb test of different freeze-thaw cycles without alum: (a) 0, (b) 1 time, (c) 3 times, (d) 5 times, (e) 7 times, (f) 9 times, (g) 10 times, (h) 15 times, and (i) 20 times.

atomic nuclei and have a small attraction to electrons outside the nucleus. When more sodium ions exist on the surface of soil particles, it will cause a significant decrease in the gravitational force of the weakly bound water layer. Because of the large number, more water molecules are attracted, so the thickness of the diffusion layer becomes larger. The cations commonly present in soils are calcium, magnesium, and potassium ions. Potassium ions have more nuclear numbers than sodium ions, and calcium and magnesium ions get higher valence than sodium ions, so all of their thickness of diffusion layers is smaller than that of sodium ions. Therefore, when the surface charge of the soil is constant, the thickness of the diffusion layer is inversely proportional to the ion valence and directly proportional to the ion concentration. Alum $\left(\mathrm{KAl}\left(\mathrm{SO}_{4}\right)_{2} \cdot 12 \mathrm{H}_{2} \mathrm{O}\right)$ contains $\mathrm{Al}^{3+}$, and the thickness of the double electric layer for $\mathrm{Na}^{+}$is three times that for it. When alum is mixed into soil, $\mathrm{Na}^{+}$can be replaced by $\mathrm{Al}^{3+}$ on the surface of soil particles, causing the reduction in the thickness of the diffusion layer and the double electric layer. Besides, the bound water film becomes thinner and the gravitational force between particles increases, which leads to the dispersion of soil decreasing. $\mathrm{Al}^{3+}$ hydration reaction generates $\mathrm{Al}_{2} \mathrm{O}_{3}$ colloids, which can cement the soil particles, fill the void, and play the role of reducing the dispersivity. It can also generate $\mathrm{H}^{+}, \mathrm{Al}^{3+}+$ $3 \mathrm{H}_{2} \mathrm{O} \longrightarrow \mathrm{Al}(\mathrm{OH})_{3}+3 \mathrm{H}^{+}$, reducing the $\mathrm{pH}$ value. The charge number on the surface of soil particles decreases, so the diffusion layer becomes thinner, which leads to the interparticle gravitational force increasing and the dispersibility weakened.

4.2. Variation of ESP with the Number of Freeze-Thaw Cycles before and after Improvement. Figure 7 shows the relationship between ESP and the number of freeze-thaw cycles under soil treated with $2.5 \%$ alum. It can be seen that when the soil is not mixed with alum, ESP ranges from $26.28 \%$ to $33.33 \%$ and gradually decreases with the increasing cycle and finally smoothes out. When alum is added to the soil, ESP decreases greatly, generally between $1.89 \%$ and $3.89 \%$, and changes little with the increase of the number of freeze-thaw cycles, increasing slowly and eventually getting gentle. The addition of $2.5 \%$ alum to the soil reduces ESP by about $27 \%$ compared to that without alum, indicating that alum has a great improvement effect on the soil dispersivity, and the soil dispersivity does not change much after experiencing freeze-thaw cycle. 


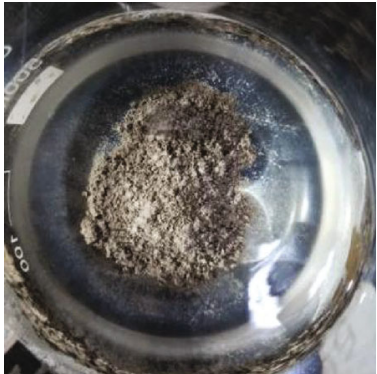

(a)

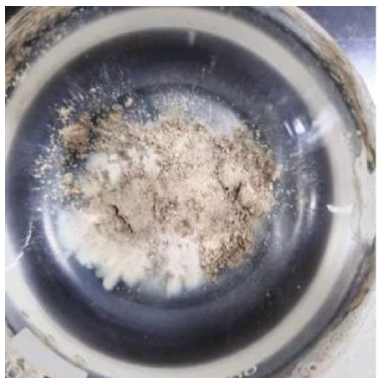

(d)

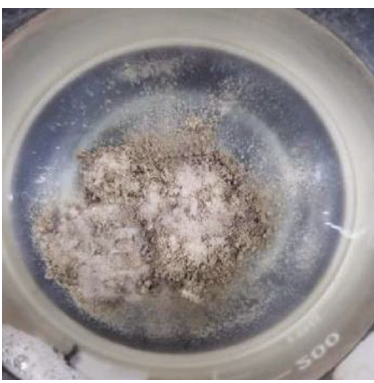

(g)

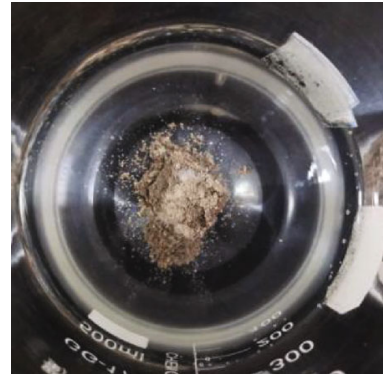

(b)

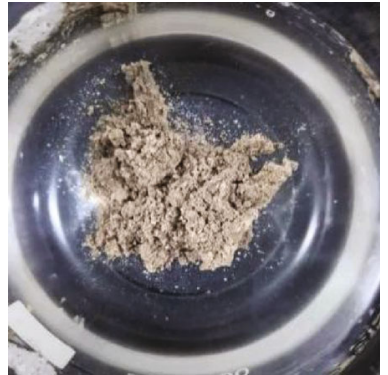

(e)

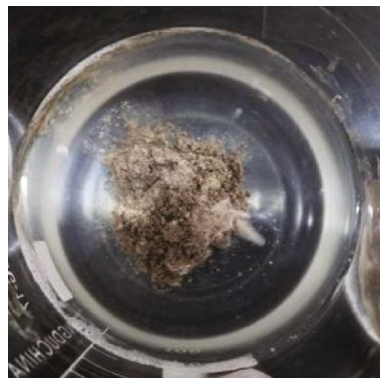

(h)

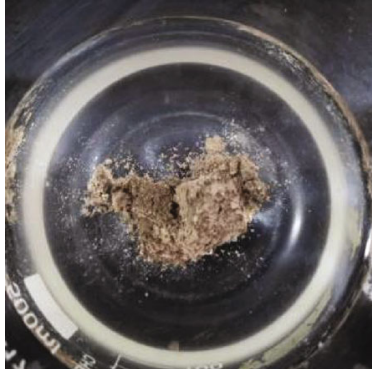

(c)

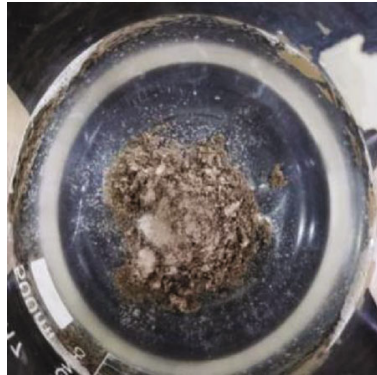

(f)

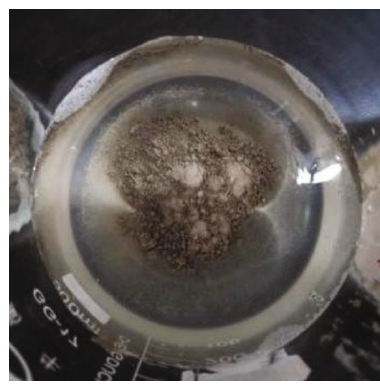

(i)

Figure 11: Results of the crumb test of different freeze-thaw cycles with $2.5 \%$ alum: (a) 0, (b) 1 time, (c) 3 times, (d) 5 times, (e) 7 times, (f) 9 times, (g) 10 times, (h) 15 times, and (i) 20 times.

4.3. Variation of Dispersion with the Number of Freeze-Thaw Cycles before and after Improvement. Figure 8 shows the relationship between dispersion and the number of freezethaw cycles under soil treated with $2.5 \%$ alum. It can be seen that when alum is not added, the overall dispersion ranges from $64.37 \%$ to $81.04 \%$, with the extreme difference of $16.67 \%$, and the dispersion increases gradually with the increase of the number of freeze-thaw cycles. When $2.5 \%$ alum is added, the overall dispersion ranges from $18.37 \%$ to $30.2 \%$, with the extreme difference of $11.83 \%$, and the dispersion increases slowly with the increase of the number of freeze-thaw cycles. The dispersion is decreased by about $50 \%$ before and after the addition of alum, and the extreme difference is reduced by $4.84 \%$, indicating that the dispersivity is greatly reduced and more stable after the addition of alum.

4.4. Variation of Pinhole Test with the Number of FreezeThaw Cycles before and after Improvement. Figure 9 shows the results of the pinhole test with different freeze-thaw cycles. It can be concluded that there is an increase in the diameter of hole with the increase of freeze-thaw cycle.
However, with $2.5 \%$ alum treated, the end hole diameter remains $1.0 \mathrm{~mm}$.

Table 7 shows the data of the pinhole test for $10 \mathrm{~min}$ under $50 \mathrm{~mm}$ water head. In the first five freeze-thaw cycles, the end pinhole diameter is less than $2.0 \mathrm{~mm}$ and the water is turbid, identified as dispersive soil. After seven times, the end pinhole diameter becomes $2.0 \mathrm{~mm}$, which is identified as highly dispersive soil. When treated with alum, the end pinhole diameter remains $1.0 \mathrm{~mm}$ unchanged and the water is clear, indicating that the results are almost not affected by the number of freeze-thaw cycles.

4.5. Variation of Crumb Test with the Number of Freeze-Thaw Cycles before and after Improvement. Figures 10 and 11 show the variation of colloidal clouding with the number of freezethaw cycles in the crumb test before and after improvement. From the figure, it shows that the colloidal clouding of untreated soil increases with the number of freeze-thaw cycles growing, and the water is practically invisible, which shows the reaction is severe. Thus, untreated soils are classified as dispersive soil. When soil samples are improved by $2.5 \%$ alum, the water remains clear, and the colloidal clouding is nearly 
completely eliminated, which determines that the soil samples are defined as nondispersive soil. No matter how many times of freeze-thaw cycles, there is no reaction of cloudy water, indicating the improvement effect is almost not affected by the number of freeze-thaw cycles.

It can be observed that the dispersibility of untreated soil is affected by the number of freeze-thaw cycles from the above figures. The influence degree increases with the increase in the number of freeze-thaw cycles. One of the reasons is that the pore water of the soil expands in volume during the process of freezing into ice, and the volume will expand by $9 \%$. The pore water freezing process destroys the original soil structure and the connection of soil particles, which cannot be restored in the subsequent thawing process, so the dispersivity of soil will increase [21-25]. What's more, from Figure 7, as the number of freeze-thaw cycles increases, exchangeable sodium ions grow, which will increase the thickness of the diffusion layer and decrease the interparticle attraction, consequently increasing dispersivity.

The dispersibility of alum-treated soil is almost not affected by the number of freeze-thaw cycles. The dispersion mechanism of dispersive soil is mainly influenced by the sodium ions and acidity of the soil. For one thing, sodium ions are replaced by aluminum ions, resulting in the decrease of the thickness of the double electric layer. During the freezing process, the bound water freezes after the free water in the soil [26]. The pore water volume expansion is not obvious due to the thinning of the weakly bound water film, which means the connection of soil particles is hardly broken, so there is no change in dispersivity. For another, the aluminum ion hydration reaction generates $\mathrm{H}^{+}$, which can reduce the $\mathrm{pH}$ values, destroying the alkaline environment required for dispersive soils. The acidity does not change with the increasing number of freeze-thaw cycles, so the dispersivity remains unchanged.

\section{Conclusions}

The soil in Qian'an area of Jilin Province is a soda saline soil with high salt content and extreme dispersion, and its durability can be analyzed through improved tests, and the following conclusions can be drawn.

(1) Dispersive soil is improved by alum, and the mixture amount is $1 \%, 1.5 \%, 2 \%, 2.5 \%$, and $3 \%$. Pinhole test and crumb test initially determined that $2.5 \%$ and $3 \%$ are the optimum mixture quantities. Double hydrometer test and percentage of exchangeable sodium ion test proved that $2.5 \%$-alum-treated soil can turn to nondispersive soil. Based on the cost issue, $2.5 \%$ is the optimal mixture content

(2) The presence of sodium ions on the surface of soil particles is the main reason for dispersion. Alum $\left(\mathrm{KAl}\left(\mathrm{SO}_{4}\right)_{2} \cdot 12 \mathrm{H}_{2} \mathrm{O}\right)$ changes the thickness of the double electric layer mainly by exchanging $\mathrm{Al}^{3+}$ for $\mathrm{Na}^{+}$on the surface of soil particles, thus reducing the distance between particles, increasing the attraction and decreasing the dispersivity
(3) The dispersibility of soil is affected by freeze-thaw cycle, and the influence degree increases with the increasing number of freeze-thaw cycles. When the soil is treated with $2.5 \%$ alum, the dispersibility is practically not affected by the freeze-thaw cycle

(4) During the freeze-thaw cycle, the pore water freezing process destroys the original soil structure and the connection of soil particles and exchangeable sodium ions grow. When the soil is treated with $2.5 \%$ alum, sodium ions are replaced by aluminum ions, resulting in a decrease in the thickness of the weakly bound layer film, and the aluminum ion hydration reaction reduces the $\mathrm{pH}$ values

\section{Data Availability}

The data used to support the findings of the study are available from the corresponding author upon request.

\section{Conflicts of Interest}

The authors declare that there is no conflict of interest regarding the publication of this paper.

\section{Acknowledgments}

This research was supported by the Key Program of International (Regional) Cooperation and Exchange of National Natural Science Foundation of China (Grant No. 41820104001), National Natural Science Foundation of China (Grant Nos. 41602285 and 41430642), and Jilin Science and Technology of Development Plan Projects (Grant No. 20180520064JH).

\section{References}

[1] H. H. Fan, L. Zhang, X. J. Yang, J. L. Ju, T. Chen, and S. X. Kang, "Advances in research and engineering appliciatons of dispersive soil," Journal of Water Resources and Architectural Engineering, vol. 17, no. 3, pp. 10-21, 2019.

[2] R. Fell, P. Macgregor, and D. Stapledon, Geotechnical Engineering of Embankment Dams, A. A. Balkema Publishers, 1992.

[3] D. Penner and G. Lagaly, "Influence of anions on the rheological properties of clay mineral dispersions," Applied Clay Science, vol. 19, no. 1-6, pp. 131-142, 2001.

[4] M. X. Gao, L. Peng, G. D. Wang, and H. H. Fan, "Mechanism and reason of dispersivity of dam soil in Nanping Reservoir," Chinese Journal of Geotechnical Engineering, vol. 31, no. 8, pp. 1303-1308, 2009.

[5] B. G. Gidday and S. Mittal, "Improving the characteristics of dispersive subgrade soils using lime," Heliyon, vol. 6, no. 2, article e03384, 2020.

[6] N. C. Consoli, R. A. Q. Samaniego, and N. M. K. Villalba, "Durability, strength, and stiffness of dispersive clay-lime blends," Journal of Materials in Civil Engineering, vol. 28, no. 11, article 04016124, 2016.

[7] S. Mohanty, N. Roy, S. P. Singh, and P. Sihag, "Estimating the strength of stabilized dispersive soil with cement clinker and 
fly ash," Geotechnical and Geological Engineering, vol. 37, no. 4, pp. 2915-2926, 2019.

[8] P. Sihag, M. Suthar, and S. Mohanty, "Estimation of UCS-FT of dispersive soil stabilized with fly ash, cement clinker and GGBS by artificial intelligence," Iranian Journal of Science and Technology-Transactions of Civil Engineering, vol. 45, no. 2, pp. 901-912, 2019.

[9] X. C. Yang, Experimental Study on Scouring of Modified Dispersive Soil in Cold Regions, Xi'an University of Architecture and Technology, 2019.

[10] H. Savaş, M. Türköz, E. Seyrek, and E. Ünver, “Comparison of the effect of using class $\mathrm{C}$ and $\mathrm{F}$ fly ash on the stabilization of dispersive soils," Arabian Journal of Geosciences, vol. 11, no. 20, p. 612, 2018.

[11] S. Premkumar, J. Piratheepan, and P. Rajeev, "Effect of brown coal fly ash on dispersive clayey soils," Proceedings of the Institution of Civil Engineers-Ground Improvement, vol. 170, no. 4, pp. 231-244, 2017.

[12] Y. J. Yan, H. H. Fan, and X. J. Yang, "Engineering characteristics of dispersive clay modified with fly ash," Journal of Hydroelectric Engineering, vol. 36, no. 4, pp. 86-94, 2017.

[13] V. R. Ouhadi and A. R. Goodarzi, "Assessment of the stability of a dispersive soil treated by alum," Engineering Geology, vol. 85, no. 1-2, pp. 91-101, 2005.

[14] ASTM D4221-11, Standard Test Method for Dispersive Characteristics of Clay Soil by Double Hydrometer, ASTM International, West Conshohocken, PA, 2011.

[15] ASTM D4647-06, Standard Test Method for Identification and Classification of Dispersive Clay Soils by Pinhole Test, ASTM International, West Conshohocken, PA, 2009.

[16] ASTM D6572-06, "Standard test methods for determining dispersive characteristics of clayey soils by the crumb test," ASTM International, West Conshohocken, PA, 2006.

[17] T. M. Petry, Identification of Dispersive Clay Soils by a Physical Test, Oklahoma State University, 1974.

[18] M. Y. Fattah, R. H. Ismael, and M. F. Aswad, "Dispersion characteristics of MgO-treated dispersive clay," Arabian Journal of Geosciences, vol. 14, no. 7, p. 605, 2021.

[19] Z. Y. Shi, H. E. Chen, X. Q. Yuan, X. H. Xu, S. Lin, and G. F. Chen, "Effect of freezing-thawing cycle on soil dispersion and analysis of microscopic mechanism," Journal of Engineering Geology, vol. 28, no. 3, pp. 482-489, 2020.

[20] M. Hassanlourad, M. N. Rokni, M. Hassanlo, and A. Badrlou, "Dispersive clay stabilised by alum and lime," International Journal of GEOMATE, vol. 12, no. 29, pp. 156-162, 2017.

[21] T. F. Hu, D. W. Liu, and H. Wu, "Experimental testing and numerical modelling of mechanical behaviors of silty clay under freezing-thawing cycles," Mathematical Problems in Engineering, vol. 2020, Article ID 9693156, 13 pages, 2020.

[22] Z. Y. Yan, W. Pan, J. J. Fang, and Z. H. Liu, "Numerical simulation of thawing process in frozen soil," Geofluids, vol. 2020, Article ID 8822320, 7 pages, 2020.

[23] X. M. Duan, "Mechanical effects of solid water on the particle skeleton of soil: mechanism analysis," Geofluids, vol. 2021, Article ID 9969023, 11 pages, 2021.

[24] X. D. Zhang, E. C. Zhai, Y. J. Wu, D. A. Sun, and Y. T. Lu, "Theoretical and numerical analyses on hydro-thermal-saltmechanical interaction of unsaturated salinized soil subjected to typical unidirectional freezing process," International Journal of Geomechanics, vol. 21, no. 7, article 04021104, 2021.
[25] X. D. Zhang, Y. J. Wu, E. C. Zhai, and P. Ye, "Coupling analysis of the heat-water dynamics and frozen depth in a seasonally frozen zone," Journal of Hydrology, vol. 593, article 125603, 2021.

[26] Y. Zheng, W. Ma, and H. Bing, "Impact of freezing and thawing cycles on structure of soils and its mechanism analysis by laboratory testing," Rock and Soil Mechanics, vol. 36, no. 5, pp. 1282-1287, 2015. 